\title{
Los conflictos en la reflexión oriental
}

\section{Conflicts in Eastern Reflection}

\section{Francisco Benavente Meléndez de Arvas ${ }^{1}$ \\ Capitán de Navío (España)}

Recibido: 03-05-20

Aprobado: 11-06-20

\section{Resumen}

El concepto "reflexión" implica individualidad y cultura. Por ello, llegar a acuerdos de mínimos en aspectos cruciales de la realidad exige un relativo esfuerzo de abstracción y de comprensión de lo diferente, particularmente si analizamos el pensamiento de pueblos que nos son lejanos.

Las filosofías orientales siguen siendo extrañas al pensamiento occidental generalizado. Sus principios rectores se vierten en un estilo de moral distinta. El cambio, dicho en abstracto, se percibe peligroso en un hemisferio y como parte de la misma vida en el otro.

En este contexto, "pensar la guerra" debe sufrir o sufre los mismos contrastes. De descubrir sus peculiaridades va este trabajo de análisis.

En nuestros días, los chinos, por ejemplo, siguen sintiendo internamente el orden del universo de raíz milenaria, budista, confucionista. La efervescencia cultural que significó la revolución comunista, aunque afectó las relaciones sociales, no pudo eliminar la ancestral inclinación de este pueblo hacia la armonía y el orden celestial. Siguen pensando la guerra en forma muy similar a sus clásicos eternos.

Por tanto, revisaremos a continuación todas estas cuestiones.

Palabras-clave: Filosofías orientales, pensar la guerra, importancia del cambio, armonía y conflicto.

\footnotetext{
${ }^{1}$ (pacon_trasgu@icloud.com) Francisco Benavente Meléndez de Arvas se encuentra actualmente retirado. Ha desarrollado su carrera operativa en el Arma Submarina. Posteriormente, participó en el proceso de profesionalización de las Fuerzas Armadas españolas tras la suspensión del Servicio Militar Obligatorio.

Se licenció en Ciencias Políticas y obtuvo el diploma de Estudios Avanzados en Ciencias de la Administración. La guerra contra la violencia, El acoso a los Estados en el siglo XXI; sociedades y estructuras y La UE; su vocación de actor global. Necesidad de transformación militar son algunas obras en las que ha participado.
} 


\section{Abstract}

The concept of "reflection" implies individuality and culture; therefore, reaching minimum agreements on crucial aspects of reality requires a relative effort of abstraction and understanding the different if we analyse the thinking of peoples that are distant from us.

Oriental philosophies remain foreign to generalized Western thought. Its guiding principles are poured into a different Moral style. The change, said in the abstract, is perceived as dangerous in one hemisphere and as a part of the essential life in the other.

In this context, 'thinking on war' must suffer or suffer indeed the same contrasts. This work of analysis goes to discover these peculiarities.

In our days, the Chinese, for instance, continue to feel the Order of the Universe in a sense of millenary roots, going from Buddhist, Confucianist. The cultural effervescence that the communist revolution meant, could not eliminate the ancestral tendency of this people towards harmony and celestial order, although if affected social relations. They continue to think on war in a very similar way to its eternal classics.

We will therefore review all these issues below.

Key-words: Eastern Philosophies, Thinking on War, Importance of Changes, Harmony and Conflict.

\section{Forma de pensar oriental}

"La cultura o civilización, en sentido etnográfico amplio, es aquel todo complejo que incluye el conocimiento, las creencias, el arte, la moral, el derecho, las costumbres y cualesquiera otros hábitos o capacidades adquiridas por el hombre en cuanto miembro de la sociedad".

E.B. Taylor, Primitive Culture

Cuando consideramos el concepto "reflexión" (forma de pensar) nos resulta claro que es bastante difícil llegar a acuerdos de mínimos en aspectos cruciales de la realidad con personas de nuestro mismo entorno: familia, empresa, comunidad académica, e incluso como nación. Por ello, entiendo que intentarlo con entornos culturales antropológicamente distantes va a exigir un relativo esfuerzo de abstracción y de comprensión de "lo diferente".

Forma de pensar oriental, ¿qué podemos decir de ello? Sostengo que es necesario revisar los fundamentos culturales antes de ir a mayores. Tendemos a pensar que la ética y la moral, desde nuestro enfoque europeo, acaso sean semejantes a las que se dan en culturas del Lejano Oriente. Decididamente no es así y me explico a continuación. 


\section{Filosofías orientales}

Dado que vamos a viajar intelectualmente "más allá del Himalaya", deberemos dejar atrás lo religioso-metafísico que resulta ser tema capital en el país del Ganges.

En el subcontinente indio, el pensamiento se caracteriza por una posición de retiro, de apartamiento de la vida: el hombre debe liberarse de la vida mediante la reflexión. La filosofía india está volcada en la finalidad: ordenar nuestra vida y conducta para liberarnos de la vida y acabar los ciclos de reencarnación. Es esta una finalidad "más allá de la vida".

El filósofo indio no tiene nada que ver con las personas de su entorno, porque está dedicado a la soledad. Poco puede, pues, influir en el desarrollo de su comunidad como no sea a través de una enseñanza exotérica. Es esta una sociedad cuyos mejores ciudadanos son unos "pasotas" con los que no se puede contar; no al menos según el sentido de cooperación interciudadana común en la cultura occidental.

Pero más allá del Himalaya la filosofía se torna práctica, fuertemente práctica y de aplicación a la vida. De hecho, su fin buscado es la conformación de la vida misma: una vida perfecta, ejemplar y armónica, que por serlo lleva a la felicidad.

Los filósofos chinos no son teólogos son educadores del pueblo, consejeros de príncipes, estadistas. Si buscan la soledad lo hacen porque no han podido ejercer esas "funciones vitales" sobre la sociedad de su época; entonces se retraen y se ciernen sobre el tao, que pasa a ser el guía de sus almas.

\section{China: el I Ching}

Pragmáticos desde el minuto uno, los filósofos chinos no se retuercen la mente especulando que pueda haber más allá de los dioses. La primera obra que producen es un libro oracular, El libro de las metamorfosis (también conocido como El libro de los cambios), el viejísimo I Ching. Significa "fuente de consulta". Su esencia lo llena todo y es reconocible en la obra de Lao Tse y de Kung Tse (Confucio).

El principio rector es dar indicaciones sobre el modo de comportarse en cada situación precisa, es pues un libro de moral. Da instrucciones para el conocimiento y perfeccionamiento de uno mismo. El libro se centra en la preocupación por el cambio constante del aspecto de los acontecimientos.

Es importante señalar que el pensamiento chino es simbólico, se mueve entre conceptos abstractos, pero posee una refinada comprensión de los sentimientos que despiertan esos símbolos. Detrás subyace un orden, una ley eterna, un principio supremo: tao, que significa propiamente "camino". 
El hombre debe ajustar su conducta a este orden eterno, debe aceptarlo y someterse a su imperio. Es una idea de carácter conservador y contemplativo, fundamental de la ética china. Pero ¿cómo hacerlo?, mejor dicho ¿cómo lo hacen?

Así como los occidentales dedicamos un considerable esfuerzo a combatir o restringir los peligros que implica todo cambio, para la mentalidad china cualquier momento es, en sí mismo, el resultado de una cadena causal que abarca hasta los mínimos detalles del devenir. Este método arcaico de afrontar la realidad, dando espacio a la aleatoriedad, es una marcada característica de esta cultura. Difícil de comprender para la forma occidental de interpretar intelectualmente la existencia.

En China, se produjo un cambio radical hacia los siglos VI y V a.C.; con una generalizada inestabilidad del poder que llevó a continuas guerras y desorden.

Un efecto importante fue la aparición de cierta movilidad social, hasta entonces inexistente. Digamos que una importante masa de "hijos del pueblo" escaló las estructuras de poder y se empoderó en cierta manera. Con ello, se hizo patente una búsqueda de la solución práctica al problema de la organización ideal de la sociedad humana.

Aun así, los pensadores de esa época no tenían tiempo que perder en estériles estudios de las condiciones objetivas de la existencia cósmica; y los problemas sociales constituyeron la preocupación primordial de toda la filosofía china de esos dos siglos. Los representantes de las tres principales escuelas filosóficas chinas de la época fueron Lao-Tse -taoísta-, Kung-Tse (Confucio) y Mo-Tse - utilitarista-.

Sin ánimo de entrar en más consideraciones que no son objeto de este trabajo, podemos señalar que de Confucio son normas tales como: "que el príncipe sea príncipe, el criado criado, el padre padre, el hijo hijo". Es decir, el hombre ha nacido dentro de determinadas estructuras de relación que dan sentido y contenido a su vida y que predeterminan sus deberes que consisten precisamente en desempeñar bien este puesto "asignado en el universo".

Potente fuerza determinista estructurativa observamos aquí. Hemos de tenerla en cuenta en nuestro análisis. Con esto en mente, no nos debe extrañar que Confucio reprobase el nacionalismo guerrero y las luchas civiles.

\section{Japón}

La filosofía japonesa no tiene raíces tan antiguas como las mencionadas, ni siquiera son milenarias. De hecho, se desarrolló bajo la influencia de la filosofía china de la naturaleza, el confucianismo, el budismo y, más tarde, el neoconfucianismo. 
Lo más significativo que se puede contar de su pensamiento es que establecen que sobre el universo impera un absoluto místico: el taikioku o mukioku -el "gran límite" o "lo ilimitado"-, fuerza universal y sobrenatural, privada de cualidades y de formas, inaccesible a la percepción humana. Este "absoluto" constituye la base del principio ideal ri (léase $l i$ ), enlazado con el principio material $\mathrm{ki}$ ( $t \mathrm{si}$ ) capaz de crear la naturaleza física de las cosas y del hombre 2 .

Han heredado del confucionismo clásico las relaciones de subordinación. Y dominaron las ideas y concepciones materialistas, debido fundamentalmente a la influencia de los pensadores occidentales que brillaban en los años del despertar filosófico nipón. Cabe así mencionar a Bacon, Hobbes, Galileo. Hablamos de una filosofía que se desarrolla en los siglos XVII y XVIII, cuestión que sorprende de alguna manera ${ }^{3}$.

Cabe aquí la pregunta esencial: ¿se desarrolla para algo o "contra algo"? Sostengo que se desarrolla como acción dialéctica enfrentada a las normas del profundo feudalismo milenario japonés. Era el tiempo del Bakumatsu, el final del periodo Edo y del shogunato. Los primeros estertores de una era milenaria y el final del sakuko, su política de aislamiento.

En la segunda mitad del siglo XIX, un elemento esencial influyó sobre el desenvolvimiento de la filosofía japonesa: su inacabada revolución burguesa en los años 1867 y 1868. Las ideas filosóficas, en dicho periodo, se fueron desarrollando en el proceso de la lucha entre los filósofos kanrió gakusia ("doctos de la burocracia") y minkan gakusia ("doctos del pueblo").

Se nos antoja, pues, que esta nación se dedicó a otras cosas que a hurgar en cosmogonías supraexistentes. La larga travesía feudal, con un orden férreo de la sociedad que lo sostenía, tal vez dedicó sus energías a otras cuestiones. Por lo tanto, aquí debemos subir un escalón y dirigir el análisis a los aspectos morales. La ética japonesa parece un arcano y es heredada de sus vecinos del otro lado del mar de China. Pero la moral es el terreno de la religión, principalmente, y en este campo nos encontramos con el sintoísmo. Se trata de la religión nativa de Japón. Se basa en la veneración de los kami o espíritus de la naturaleza. Hay kami que son locales, conocidos como espíritus de un lugar en particular y otros representan objetos naturales mayores y también procesos. A esta especie de animismo naturalista se superpone una profunda veneración a los antepasados que se identifica intensamente con la cultura ancestral japonesa.

Lo que transciende, de interés para nuestro análisis, es la potencia del ritual o rituales, puesto que son la esencia de este pueblo. La otra obsesión son las prácticas de purificación, la obediencia al orden que fluye del cielo y arregla

\footnotetext{
${ }^{2}$ Descripción más amplia en: http://www.filosofia.org/enc/ros/filos18.htm

3 En el siguiente enlace se expone cómo interaccionó la filosofía occidental de entonces con el pensamiento japonés: http://www.filosofia.org/urss/dfm1946.htm
}

Araucaria. Revista Iberoamericana de Filosofia, Política, Humanidades y Relaciones Internacionales, año $22, \mathrm{n}^{\circ} 44$. Segundo semestre de 2020. Pp. 473-494. ISSN 1575-6823 e-ISSN 2340-2199 https://dx.doi.org/10.12795/araucaria.2020.i44.22 
la Tierra. Este orden surge de las normas morales religiosas y llena la vida y las artes japonesas, incluidas las marciales. Es la esencia, así mismo, del código ético del bushido, trasciende la religión y llena la norma militar de los bushi, llamados, en Occidente, samuráis.

Y como vamos de guerra y conflicto es bueno una breve mención a la esencia de este código bushido: lealtad y honor hasta la muerte; aceptar la muerte como parte del orden celeste que rige la Tierra. La correcta traducción de bushido no es "código samurái" sino el camino; y este término, que ya ha sido mencionado antes, cierra un círculo de su forma oriental de pensar el universo.

Señalo que nos limitamos a estos dos países por ser representativos de la zona objetivo $^{4}$, por la gran influencia milenaria de uno y por el enganche tardío, en forma de vagón de cola, del otro; así como por ser muestra suficiente para el análisis que se pretende.

\section{Interpretación de la guerra en el pensamiento clásico oriental}

En las culturas que se basan en filosofías morales de raíz pacifista que arraigan sus principios y valores en formas peculiares de religión trascendente, siempre se detecta una delicada relación dialéctica con los asuntos de la guerra y los conflictos.

Por ello, podemos interpretar a priori que, en el caso de China, ese "orden superior" que rige los destinos de las personas y les impulsa a desarrollar su vida en el puesto que en ella tienen asignado, implica que la guerra pueda llegar a ser entendida como algo estresante: como un fallo o fractura de la "armonía celestial".

Otro aspecto que debe atraer nuestra atención es escrutar de qué manera la actitud ante estos asuntos puede verse modificada al contactar con otras las culturas, si la interacción alcanza un nivel tal que permita que superen sus reglas esenciales originarias. Para empezar, sostenemos que la guerra es un acto político, un hecho social y sus singularidades culturales deben ser consideradas en el análisis.

En el caso chino, cuando acaeció el momento en que los conflictos dejaron de ser locales y abarcaron totalidades superiores, reinos enteros, hemos de suponer que se produjo una reflexión inevitable. Cómo no, si alteraba la armonía predicada por sus filósofos, consejeros de príncipes.

\footnotetext{
${ }^{4}$ Corea se hace visible en el siglo $\mathrm{X}$ de nuestra era. Fue básicamente imperial a estilo japonés y bastante introvertida como nación; y su moral es budista.
} 
En Japón, lo medieval se extendió en el tiempo como se ha señalado. Probablemente porque accedió a un "pensamiento superior elaborado" mucho más tarde y por importación del que ya había procesado su vecino chino.

En la tradición medieval europea, la idea de caballero embebe la función militar. Es una imagen idealizada que actúa a través de un código ético y abarca la idea de servicio público (que prestan las Fuerzas Armadas bajo el concepto de "acto de servicio"). En el caso japonés, esta construcción intelectual alcanzó caracteres épicos y se convirtió en la justificación de cualquier acción, incluida la pérdida de la vida en combate. El nombre del guerrero arquetípico, el samurái, deriva del verbo saburau que viene a significar "servir como ayudante" en un entorno de clase nobiliaria ${ }^{5}$.

Uno se siente tentado a pensar que la posición legendaria, casi homérica, que recreó durante centurias el guerrero emblemático japonés, ocurrió porque ninguna otra idea fuerza existió en los años del sakoku. Pero sorprende la barroca elaboración y desarrollo que alcanzó, hasta el punto de que el bushido, "el camino (do) del guerrero (bushi)", supone entre otras cosas una ética y una práctica específica de una casta y, por ende, una ideología estructurada y centrada sobre un tipo de comportamiento moral. $Y$ esto es pensamiento denso basado en ideas fuerza, pensamiento sobre el sentido de lo correcto que se postula como estilo de vida: un camino en toda regla.

El concepto tras el do japonés es un método de aprendizaje que incluye el arte del combate cuerpo a cuerpo, pero ligado a las artes estéticas, menos violentas. Podemos considerarlo un adiestramiento dirigido a la realización personal completa, una actividad de perfeccionamiento a través de una práctica íntima e intensa que requiere dedicación diaria para su interiorización.

La realidad social del Japón de esa época era una estructura estratificada con un pueblo llano igualmente estratificado, sobre el que se situaba la clase militar, los bushi, divididos a su vez en múltiples niveles y que, al comienzo de la era Meiji (1868), Nitobe cifra en unos dos millones de personas. Por encima de todos ellos estaban los militares nobles, daimio, y en la cima de la pirámide los nobles de la Corte, los kugé ${ }^{6}$.

El contraste entre ambas culturas es llamativo porque una va "de lo general a lo particular", la otra recorre un camino inverso. La primera atrae la mente racional de manera inmediata con un reto ideológico de densidad e intensidad sugestivas, mientras que lo japonés es épico, ensalza y canta al perfecto guerrero autodisciplinado en el honor hasta la muerte.

\footnotetext{
5 Javier Hernández-Pacheco,"Oficial y caballero. El paradigma militar en una cultura posheroica" en VV.AA. En una sociedad posheróica: la transformación del paradigma militar. Monografía del CESEDEN núm. 127.

${ }^{6}$ Federico Aznar Fdez-Montesinos, "Bushido y Valores Militares".
} 


\section{Principios y valores culturales}

En nuestros días, los chinos siguen sintiendo internamente el orden del universo de raíz milenaria, budista, confucionista. La efervescencia cultural que supuso la revolución comunista, aunque afectó al eje circular de relaciones sociales, no pudo alcanzar de forma efectiva las relaciones en el eje radial ${ }^{7}$. Difícilmente podía conseguirlo si se piensa en cómo funcionan las cosas en la capa basal de una sociedad política ${ }^{8}$. En esencia podemos detectar que sigue presente la inclinación a la armonía y al orden. El intenso adoctrinamiento marxista no pudo penetrar esta realidad moral porque las esencias intrahistóricas cambian en rangos de siglos.

Del mismo modo podemos señalar que, en este contexto, la permanente aspiración al razonamiento lógico esencial del pensamiento occidental, como valor profundamente enraizado en nuestra cultura, resulta incomprensible desde la óptica china sumergida en su I Ching. El afán de debate y contraste de pareceres, la contraposición de opciones y opiniones, tan propia del modo de pensamiento occidental, democrático, les parece a los chinos mera palabrería, innecesaria para alcanzar objetivos cualesquiera. Y es que, desde su postura confuciana, que les inclina al equilibrio y al rechazo del conflicto, esta forma de interactuar en el seno social es un simple desperdicio.

Los valores ético-morales chinos se orientan al desarrollo equilibrado de la sociedad. Estos valores son principalmente: benevolencia, caridad, tolerancia, lealtad, reciprocidad, justicia. En esencia son valores humanos. Pero China sigue sintiendo un respeto reverencial por la jerarquía, la familia, los antepasados y la tradición; y en esto marcan una diferencia primordial.

También es notoria su inclinación al estudio, la meditación, la introspección, el autocontrol, el equilibrio, la armonía, la ausencia de conflictividad y la aspiración al "justo medio", concepto este esquivo a la mente occidental; y en esto siguen marcando diferencias importantes.

Por otra parte, para el confucionismo, la jerarquía no puede ser únicamente social. Debe ser también moral: "quien mejor practica las virtudes esenciales es un hombre superior", y son estos los que tienen la misión suprema de dirigir a la sociedad y de ocupar los cargos públicos. Se establece con ello la base ideológica de una jerarquía de carácter ejemplarizante. Cualquiera puede observar que este principio es la situación presente en la China de nuestros días.

Queda sentado, pues, el campo de la diversidad intercultural, con mención de las importantes consecuencias derivadas, si hablamos del mundo de los conflictos.

7 Gustavo Bueno Martínez, Cuestiones proemiales. Disponible en: www.filosofia.org/filomat/ df244.htm

${ }^{8}$ Gustavo Bueno Martínez, Teoría de la Sociedad politica y del Estado. 
Resaltan para nuestras intenciones de análisis: la norma de preservar el equilibrio y la armonía, eludir discusiones y conflictos; el protocolo estricto y la conciencia de la propia misión en el mundo; la expresión educadamente contenida inspirada por la autodisciplina y el autodominio; la exaltación de la lealtad a la jerarquía.

\section{La guerra, las estrategias}

Del capítulo II del clásico El arte de la guerra de Sun Tzu, extraemos las siguientes materias que resaltan de forma expresa: logística, costes de la guerra y sus consecuencias, la guerra ha de ser corta - "todavía no hemos visto una operación inteligente que fuese prolongada"-, el combate encarece la economía.

Cualquier estratega moderno acepta estas cuestiones sin reparos. Hoy nadie duda que una guerra consume los recursos existentes y no genera otros nuevos, la guerra es un acto político antieconómico. Ya lo era hace más de 2.500 años para los expertos de entonces. Este enfoque nos obliga a centrar el análisis en los delicados equilibrios entre lo que es una "guerra de duración útil" y una "paz sin excesos".

La obra de Lü Shang (conocido también como Jiang Ziya), otro clásico, nos enseña cómo entendían lo estratégico. Shang distinguía seis formas de estrategia. En "lo civil" explica cómo debe organizarse el Estado para proveer una apropiada base logística, fundamento de cualquier necesidad posterior de expansión militar. Volvemos, una vez más a las ideas-fuerza de la cultura china: ajustar la economía reduciendo el dispendio de recursos, promover apropiados valores y reglas de comportamiento en la población, el equilibrio de "premios y castigos reglados", un clásico chino; actuar con dignidad y evitar alterar y perjudicar al pueblo.

Que privilegie la estrategia “civil” es ya toda una declaración de intenciones que nos da que pensar. Pero aún asombra más cuando expone sus objetivos de la estrategia militar: elaborar planes para provocar desafección en el enemigo y captar a los descontentos, usar subterfugios y técnicas de guerra psicológica para manipular su población y causar su abatimiento, cultivar visiblemente la virtud y establecer políticas que se ganen el corazón y la mente del pueblo: "Esta es la vía en la que el Estado ganará la victoria sin una sola batalla.".

$\mathrm{Da}$ al resto de aspectos de la estrategia nombre de animales totémicos para describir aspectos relativos a "lo militar": organización, armamento, táctica, asuntos relativos al mando, estudio del terreno. Todos ellos temas eternos de los tratadistas militares chinos. 
Que sean de nuestro interés sobresale el énfasis que siempre pone en la necesidad de flexibilidad y heterodoxia como vía de mantener el control del espacio y los hombres. Repite una y otra vez que el funcionamiento efectivo del buen gobierno deriva de una visión estratégica centralizada y ordenada, visión que debe estar bien informada, apoyada en comunicaciones efectivas y en el secreto.

De la flexibilidad deriva la capacidad de maniobra, rapidez de acción decididamente ejecutada, astucia y engaño en la maniobra, uso de emboscadas, maestría en el empleo de tipos de fuerza diferentes según la situación y el terreno.

La heterodoxia busca superar en cada caso la acción enemiga, enfrentar fuerzas superiores, nunca repetir tácticas, explorar continuamente las fortalezas y debilidades propias y del enemigo y actuar en consecuencia. Para Lü Shang, no hay "manuales de empleo", solo rige en el campo de batalla el arte del general.

\section{La justificación de la guerra}

Los debates sobre las "causas justas" son antiguos y conocidos en Occidente. En Oriente tenemos una primera aproximación en la obra de Sima Rangju'. En su obra Los métodos de Sima, también conocida por El arte del mariscal de guerra afirma que la guerra es necesaria para la existencia del Estado y que su explotación concienzuda es el fundamento del poder político.

Sostiene así mismo que el equilibrio entre guerra y paz es vital para la prosperidad del Estado y que "los que descuidan a sus ejércitos perecerán"; pero, atención, añade, "tan rápidamente como los que recurran a la guerra con demasiada frecuencia". Rangju sostiene que la guerra es una necesidad desafortunada para alcanzar la paz; es decir, en la moral china de Sima, sin guerra no hay Estado, pero con excesiva beligerancia tampoco. No es un mal principio para comenzar y es digno de ser tenido en cuenta.

Lo que subyace es la aceptación, como hecho natural, de la diferencia de roles entre "lo civil" y "lo militar" por sus valores inherentes contradictorios. No está claro que el autor entienda que está en riesgo la imprescindible "armonía celestial", más bien parece que centra el asunto en cuestiones de yin y yang. De hecho, alerta sobre la inevitable decadencia del Estado "si los civiles actúan como soldados y si los soldados actúan como civiles"10.

Del concepto de utilidad surge un pensamiento poderoso sobre justificaciones: para que la guerra sea legítima debe beneficiar al pueblo. En

\footnotetext{
${ }^{9}$ Famoso general chino de la era de las primaveras y los otoños.

${ }^{10}$ No establece con claridad la diferencia entre unos y otros; la da por sentada. Considera lo civil y lo militar dos esferas con vida propia dentro del Estado.
} 
puridad, el autor exige que beneficie a los pueblos de los Estados involucrados, por lo que exige -interesante pensamiento- que se eviten acciones de guerra que dañen la población del enemigo y prohíbe severamente actos inamistosos contra una población sometida. La razón de estas propuestas, tan extremas como llamativas, radica en que Sima solo admite la guerra "para eliminar un Gobierno protervo". Casi suena kantiano.

Que elija a Sima antes de trasladarme, en un salto de unos 2.500 años, a nuestros días es intencionado. Veamos qué diferencias podemos encontrar en el pensamiento de los tratadistas actuales.

\section{Interpretación de la guerra en el pensamiento oriental actual}

Considero suficiente la mención hecha al pensamiento clásico. Es obvio que puede ser mucho más extenso, pero siguiendo sus propios consejos seamos heterodoxos y flexibles, demos por bueno el conocimiento adquirido y viajemos varios milenios en el tiempo hasta el presente.

Y lo primero por considerar es que las circunstancias cambiantes del desarrollo tecnológico han introducido, en mi opinión, un sexto factor a los cinco clásicos de los tiempos de la Golden Era de la dinastía T'ang: las técnicas high-tech, las guerras de alta tecnología. Cabe preguntarnos qué significa esto en la mente oriental.

\section{Pensamiento militar contemporáneo}

Los autores militares chinos de nuestros días siguen fundando su pensamiento en sus clásicos. Es una lógica que enlaza con la tradición, reverenciada en esos países. Parece seguir existiendo un rechazo natural a la inclinación al conflicto, si nos atenemos a sus prólogos.

Si su "escuela" es flexibilidad y heterodoxia; si su estrategia básica es conocer el terreno y las debilidades y fortalezas de unos y otros; cuando leamos a sus pensadores de hoy deberemos buscar las esencias que ambos antecedentes vuelcan en sus obras.

\section{La realidad según ellos}

Debo señalar que los actuales escritores de textos militares ven inquietos cómo evoluciona un factor básico de sus clásicos: el Estado. Factor que pasa, en ellos, de "constante" a "variable", cuando no a "incógnita". Les sorprende que la globalidad" haya sembrado "la realidad tangible" de nuevos entes en

11 Nuestro mundo tras la implementación de la globalización, generalizada en el siglo XX. 
forma de estructuras organizadas ajenas a la regulación estatal. Les inquieta la proliferación de organizaciones intergubernamentales (OIG) de todo rango y condición, en cuyo seno "el poder estatal" languidece y agoniza.

"Poder" y "regulación" son variables íntimamente incrustadas en su concepto de armonía. Que ahora queden al albur de relaciones extraestatales es algo que les conmueve. Y si la "guerra justa" se hacía necesaria para evitar gobiernos protervos, empiezan a comprobar que el progreso ya no permite pensar en la guerra como foro último de apelación y debate.

Y, lo primordial, ven en todo ello un reto definitivo a la autoridad. Un amenaza a la idea tan suya y querida de autoridad nacional como fuente de regulación jurídica y de armonía esencial. Un peligro para los intereses nacionales, para la virtud que nutre la voluntad de la nación ${ }^{12}$.

\section{El nuevo paradigma del statu quo internacional}

En nuestros días, cualquier medio, ya sea diplomático, económico o político tiene suficiente fuerza para suplantar el papel de los medios militares.

Queda, pues, roto el equilibrio del yin y yang, de lo civil y lo militar. Sima clamaría su regla: "la nación declinará si los civiles se comportan como militares". Liang y Xiangsui aseveran ${ }^{13}$ que la humanidad no tiene razones en absoluto para estar contenta con tal estado de cosas, porque lo que ha implementado la globalidad es la generalización del campo de batalla, que hoy es la Tierra entera. Se ha generalizado un "estado de guerra sin derramamiento de sangre" que ocupa todo el espacio. Las personas ya no están seguras en ninguna parte del globo. Afirmación que no sorprende hoy a nadie, sea o no experto en temas de polemología.

Me resulta llamativa esa diferenciación entre guerras sangrientas/no sangrientas, porque abre nuevas vías a las estrategias de enfrentamiento. Si sus clásicos consideraban la victoria como el objetivo de la guerra, cabe preguntarse qué piensan de ello los autores militares de hoy.

\section{Tipos de guerra, caminos "distintos" hacia la victoria}

Partiendo del escenario globalizado que perciben, los autores comprenden que encarar un conflicto que se puede desenvolver en campos de batalla sin límites definidos supera "lo militar y armado" si se pretende garantizar la seguridad nacional.

\footnotetext{
${ }^{12}$ Qiao Liang y Wang Xiangsui, Unresticted Warfare, 1999.

13 Op. cit.
} 
Se trata de una visión estratégica de sentido amplio en función de la variedad de intereses nacionales en juego. Se acabó la guerra militar, bienvenido el conflicto plenario ${ }^{14}$ en el que la entera nación será forzosamente actora.

Discrepan, y me parece razonable, de los últimos estudios sobre Revolution in Military Affairs (RMA), aunque el esfuerzo tecnológico en el desarrollo de armamento parecía ofrecer respuestas para alcanzar modos de guerra menos brutales con reducción del número y gravedad de bajas, tal cosa no se ha producido. La guerra sigue mostrándonos una cara feroz. A la guerra de hoy, a pesar de todo y por desgracia, podemos categorizarla como una guerra sin restricciones.

Las variables que citan como inductoras de esta visible transformación son los cambios en el armamento. Hoy aportan una mayor letalidad y capacidad destructiva, hasta tal punto que han hecho descarrilar los viejos principios de la guerra, inmutables desde Sun Tzu a Napoleón. Por cierto, a este último le recriminan no haber escrito su prometido libro sobre este asunto. Perciben el surgimiento de otros "principios nuevos" que hoy resultan extraños para los militares.

El cambio se produce, según los autores, en la cercanía temporal de la primera Guerra del Golfo. Citan dos conceptos que consideran enfrentados: uno americano -full-dimensional operations - y otro chino - guerra combinada "más allá de los límites"-.

\section{Qué significa la propuesta "guerra combinada "más allá de los límites"}

Como su propio nombre indica proponen saltarse todas las restricciones en el combate. Algo inquietante, qué duda cabe.

Mas añaden un "pero": cuando se lleven a cabo acciones de combate se deben cumplir inexorablemente los principios esenciales que únicamente en situaciones excepcionales podrán ser obviados.

\section{Principios esenciales "más allá de los límites"}

Detectamos de nuevo su inclinación a la armonía, al eterno yin-yang, en el proceso de elaboración de sus principios esenciales: "En el proceso deductivo sobre reglas de guerra ponderamos la aparición de algún tipo de modo de combate, y este proceso nos aporta un principio que surge a lo largo de él".

Pensar reglas de guerra, aportar nuevos métodos de combate, deducir principios esenciales aplicables; todo ello parece un potente proceso de introspección.

\footnotetext{
14 Término que me invento para dar a entender una totalidad holística.
} 
Siguen con un modo armonioso de análisis, porque nunca pecarán de soberbia. La hybris es un pecado intelectual que se da más en Occidente. Consideran que todo este esfuerzo intelectual en la deducción de principios no garantiza el camino a la victoria. Pero su "pensar la guerra" con la mente abierta, es para ellos un proceso teórico indispensable para perfeccionar el modo de combatir.

En el caso que nos ocupa sus hallazgos son los siguientes:

\section{Omnidireccionalidad}

Como punto de partida de esta propuesta de guerra aconsejan: actúa a "modo de máscara" en esa forma tan del gusto de la cultura china, del arte del fingimiento.

Al tiempo, debe conocerse todo lo relacionado con el conflicto sin puntos ciegos, sin espacios oscuros u ocultos. Ya no hay distinciones entre lo que es y no es, o será o no será, "campo de batalla" en el futuro o ya mismo.

Omnidireccional también significa que se considera lo tangible, lo intangible y la tecnología que conecta ambos conceptos. Omnidireccional significa que tienen vocación de actuar en los ejes circular y radial del espacio antropológico ${ }^{15}$, ampliando los límites de la guerra clásica.

Considero importante esta circunstancia. Mucho más si son ellos quienes asignan carácter esencial a este principio como punto de partida de la guerra $\sin$ restricciones.

La violencia en relación con los ejes del espacio antropológico nos aporta visiones que amplían nuestra percepción. Para que exista violencia debe preexistir un estado de equilibrio sobre el que ella va a actuar. Y esta cuestión es aceptable para ambas visiones culturales: "equilibrio y armonía/violencia y conflicto" son caras de la misma moneda. Al fin y al cabo, la cultura humana, las culturas, son entre otras cosas un relato de operaciones violentas a lo largo de la historia.

En mi opinión, la fusión de la "violencia circular" cuya expresión máxima es la guerra sin límites y la "violencia radial" que hace uso intensivo de recursos, nos anticipa que la categoría "guerra combinada "más allá de los límites"” tiene vocación de alcanzar todos los recovecos del espacio antropológico. El pensamiento del maesse Niccolo se nos viene a la mente de natural, si tenemos en consideración su desprecio por las limitaciones morales y su consejo al príncipe de acción irrestricta en la consecución de sus objetivos.

Y si nos cuesta entender los vericuetos de la cultura oriental, lo mismo les sucede a ellos con la nuestra. Lo demuestran al asignar al florentino una actitud que rompía con la romántica idea de los combates de caballeros o su

${ }^{15}$ Gustavo Bueno Martínez, Teoría Sintáctica del Poder Político. Disponible en: www.filosofia.org 
“declinante tradición”. No parecen conocer a otros pensadores más profundos y que fueron fuente de inspiración del Renacimiento italiano, como el español Baltasar Gracián. Tampoco comprenden las relaciones de poder y los equilibrios del derecho de gentes que impusieron en Europa los reyes de España.

Irónicamente, la leyenda negra cuya finalidad era servir de herramienta de resistencia política trastocando y reescribiendo la realidad de la regulación imperial ha terminado por "oscurecer" el análisis de los estrategas chinos actuales que se tragaron este "anzuelo" y su cebo envenenado. De fuentes turbias, malas conclusiones.

A este tenor es lógico que les resulte arduo comprender los argumentos de los "títulos justos de la guerra" establecidos desde el discurso católico y evangélico con su dialéctica eterna entre "lo justo" y "lo necesario". Algún día deberemos explicárselo.

Así pues, lo omnidireccional en la mente china va por otros derroteros. Ni Confucio ni Mozi les sirven ya. Los legalistas ${ }^{16}$ al estilo de Han Fei Tzu resultan más prácticos. Por lo tanto, ya no cuenta ni predicar con el ejemplo ni la creencia en una hipotética bondad natural humana. Solo queda pues admitir que las personas actúan para alcanzar ganancias y evitar castigos, aunque suene cínico en el sentido clásico. De ahí a proponer un modelo de Estado que ponga el acento en el bienestar social de la nación por encima de los derechos individuales solo hay un pequeño paso.

\section{Sincronía}

Incluye un concepto añadido o consustancial: "mismo periodo de tiempo", porque no se trata de sincronizar los relojes, sino de establecer el "tiempo de guerra designado" para las operaciones omnidireccionales.

\section{Objetivos limitados}

Los objetivos señalados han de ser siempre menores que los medios disponibles. Un poco simple parece, pero solo parece. Se pliegan a sus clásicos más conocidos.

Por lo tanto, recomiendan no fijar objetivos irrestrictos en tiempo y espacio. Tampoco aquellos que no se merezcan tal categoría o no se puedan acometer, aunque sean de interés. Parece una obviedad, pero es muy complejo este consejo.

Ejemplarizan con lo ocurrido en Corea (1951), Vietnam (1964) y Afganistán (1978) en los que los objetivos superaron los medios disponibles; así como con la declaración de 1996 de la Administración Clinton que señaló

${ }^{16}$ El legalismo es propio de la época que va entre los siglos V al II a.C. 
como objetivos cuestiones que no merecían tal clasificación. Sí lo era el "interés nacional" y no en absoluto su sense of values (que incluso es difícil traducir a un concepto comprensible).

Según expresan, no limitar los objetivos en el sentido que le dan en este principio es la senda que lleva a una nación a la tragedia.

\section{Medios ilimitados}

Es el yang de la ecuación que sigue por lógica. La visión armoniosa implica el empleo irrestricto de medios para alcanzar los objetivos limitados. Es una propuesta de lo más racional. Para que nos entendamos, lo consideran ultima ratio en el empleo de medios, su "última frontera" en una estrategia beyond limits.

Subyace un principio filosófico esencial: los medios empleados deben servir sí o sí para alcanzar el objetivo (limitado) previsto y no exceder esta consecución. Esto suena confuciano.

La idea es potente porque centra en los objetivos el esfuerzo racional de pensar la guerra. Es propio de sus clásicos cuya sabiduría rezuma en cada palabra. Es decir, racionalicemos los objetivos -limited objetives-y después actuemos con la energía del agua que se desploma por la torrentera y con la velocidad del rayo, implementando medios más allá de los límites, pero sin vulnerar el planteamiento de objetivos.

O sea, nos ofrecen una estrategia irrestricta en los medios y cómo emplearlos, pero contenida y racional en los objetivos, planificados, limitados. No podía ser de otra manera sin alterar las normas de la armonía eterna, pienso yo. Pero alertan que tampoco debe caerse en el vicio opuesto. El empleo restringido de medios resulta tan nefasto como superar los límites impuestos a los objetivos. Insisten: "limita los objetivos, pero actúa "más allá de los límites" en la disposición y utilización de medios".

\section{Asimetría}

En realidad, lo llaman "no equilibrado" (distinto que desequilibrado, en chino), asimetría es lo más parecido a este concepto en la visión anglosajona.

De hecho, se trata de un principio que actúa como pivote, o punto de apoyo y balance, para describir las reglas de los conceptos "más allá de los límites". Significa elaborar un plan en oposición a la idea de simetría equilibrada y desarrollar la acción de combate en esa línea de pensamiento.

Lo que se pretende con este principio es favorecer el descubrimiento de los puntos débiles del enemigo y explotar esa ventaja. Es el principio más útil para los débiles. 
Los autores no lo desarrollan de modo claro y caen en tópicos clásicos usados en la exposición occidental de lo asimétrico en conflictos.

\section{Consumo mínimo}

No emplear más que los medios suficientes para alcanzar los objetivos, significa en primer lugar anteponer lo racional al ahorro. La logística de las operaciones quedará señalada por la forma de combate elegida.

Es un principio asentado en la racionalidad para el señalamiento de objetivos y en el consecuente uso de recursos. Debe insistirse en que no hablamos de ahorro de recursos y medios, sino de ajuste racional de su empleo a los objetivos señalados y definidos racionalmente teniendo en cuenta los recursos disponibles; es una dialéctica dual y balanceada.

En resumen, la forma de aplicar cabalmente este principio consiste en elegir un modo de combate que resulte en el empleo racional de los recursos de guerra disponibles. No hacerlo llevaría inevitablemente a un despilfarro de medios y una baja eficiencia. Se trata de combinar las capacidades superiores de varios tipos de acción, en varias clases de áreas, para crear una forma de combate completamente nueva que nos permita alcanzar los objetivos señalados mientras minimizamos el consumo de recursos.

\section{Coordinación multidimensional}

Significa coordinar y asignar todas las fuerzas que podemos movilizar, tanto en el ámbito militar como no militar, para batir un objetivo.

Es otro aspecto incluido en el principio inicial de sincronía: coordinación y cooperación de múltiples fuerzas en múltiples escenarios para alcanzar los objetivos. Es un principio ampliamente recogido por todos los manuales al uso.

La novedad de la propuesta de los autores es que, si consideramos que cualquier escenario puede acabar siendo "campo de batalla" y que cualquier fuerza puede ser usada bajo condiciones de "combate", deberemos entender la coordinación multidimensional como aquella que aplicaremos entre la dimensión militar y varias otras no militares en la consecución de un objetivo específico; aunque la acción militar deba ser considerada en todas las guerras como la forma de acción primordial.

Concretando: "si decides "ir más allá de los límites" no te quedes corto, porque tan malo es lo uno como lo otro".

Resulta interesante el ahínco con el que explican la complejidad de este principio. Señalan la necesidad urgente de ampliar el campo de visión respecto de las fuerzas movilizables, especialmente las no militares. Poner atención al empleo de recursos estratégicos intangibles tales como los factores geográficos, 
el papel de la historia, la cultura y sus tradiciones, el sentimiento de entidad étnica, etc. Y no solo eso, sino también ser capaces de interconectar y coordinar todos los niveles de acción desde la política de guerra hasta las tácticas.

\section{Ajustes y control del proceso completo}

Quieren expresar que a lo largo de la guerra es imprescindible un proceso continuo de inteligencia para el ajuste y control de la situación. Es la forma de afrontar la aleatoriedad de los sucesos con creatividad. Consideran que es absurdo y naíf entrar en acción encorsetados en planes rígidos predeterminados.

Este consejo me trae a la memoria conversaciones con amigos que han trabajado en países orientales, en líneas aéreas para ser más exactos, tras la diáspora que el cambio de ciclo económico alumbró con el nuevo siglo. Educados en métodos West style propios de sus compañías anteriores, repletos de normas de seguridad IATA ${ }^{17}$, pasaron un duro periodo de adaptación a la mentalidad oriental. Para resumir, antes tenían que cumplir todas y cada una de las normas de un pesado tomo de seguridad y además ser rentables a las compañías, protegidos por la regla safety is paramount. En sus nuevas compañías tenían que ser rentables y "no incumplir" una corta lista de reglas actuando con profesionalidad, porque esta característica era la causa por la que habían sido contratados. Quiere esto decir que los warning que recibían de sus nuevas compañías ocurrían por situaciones que les costaba comprender. Si esgrimían el argumento safety, la respuesta solía ser del tipo: "los hemos contratado porque los consideramos profesionales de valía contrastada y la compañía espera que se comporten como tal”. El warning se mantenía y, en la mayoría de ellas, un segundo aviso implicaba el despido. Un claro reflejo de contrastes culturales.

Si repasamos las formas de redactar las ROE en ambos extremos del mundo, es posible que encontremos circunstancias parecidas. En este apartado, el consejo se centra en que lo que espera la "compañía" es que se mantenga la iniciativa con puño firme.

Es interesante que relacionen este concepto con el de sincronía. Existe una relevancia entre estas nociones en función de su orden de presentación en el texto. En este caso la sincronía prevalece sobre el ajuste y control.

Por las mismas razones ya explicadas que caracterizan la guerra moderna -alta tecnología, extensos escenarios, variadas capacidades involucradas, extensión y alcance de la información disponible- el ajuste y control es cuestión de conseguir habilidad en ello.

17 The International Air Transport Association (IATA). 
Proponen confiar más en la intuición que en la deducción matemática ${ }^{18}$. Esto resulta extraño a la mente occidental, pero se debe a que tienen en mente la opción de cambiar el campo de batalla a la esfera "no militar" como resultado de la aplicación de un completo juego de ROE que no solo se fija en los despliegues puramente militares de armas.

Así entienden la "guerra combinada, más allá de los límites", la interpretan como el uso de estos métodos de combate, extraños y completamente nuevos, que llevan a la victoria. Y, como siempre, el consejo chino clásico y eterno: "La victoria no está garantizada por la simple aplicación de los principios arriba señalados; pero violarlos asegura la derrota. Si no hay un principio que garantice la victoria, solo podremos contar con principios esenciales, deberemos recordar esto siempre".

\section{Conclusiones}

Se puede sostener que el pensamiento estratégico oriental, según lo entienden culturalmente, es una evolución del clásico y no una revolución, a pesar de la era Mao.

Resaltan sus inquietudes como observadores del escenario internacional de nuestros días. Dos particularmente: la globalidad y el desarrollo extraordinario de la computerización, por el efecto rompedor del statu quo anterior debido a la aparición de una miríada de empresas y OIG y ONG que retan a los Estados y su soberanía.

Los progresos de la humanidad, especialmente la descalificación de la guerra como "corte de apelación" potencial, o ultima ratio, en la resolución de conflictos, ya no sirven para superar los nuevos desequilibrios.

Consideran que el "efecto integrador" de estos factores es omnicomprensivo y profundo. Y ven que la aparición de una ruda y novedosa forma de "ilustración" hace que muchos conceptos, antes básicos, del equilibrio internacional se verán inevitablemente alterados y otros desaparecerán.

Consideran especialmente frágiles las posiciones de autoridad y las fronteras; y temen la disolución de esos espacios en los que las naciones son actores principales.

Dan por acabada la arquitectura estatal que nació en la Paz de Westfalia, en 1648, demolida por el surgimiento de un gran número de organizaciones metanacionales, transnacionales e incluso no-nacionales. Y consideran que estas circunstancias inducen fuertes contradicciones y retos en la realidad

\footnotetext{
${ }^{18}$ A leer este consejo me vino a la memoria inmediatamente la rancia explicación de mis tiempos de Escuela naval, cuando el profesor intentaba hacernos comprender la importancia de la matemática en los “juegos de guerra” durante las batallas del Pacífico en la Segunda Guerra Mundial.
} 
de nuestros días. De estos retos subrayan uno muy especial que puede ser fulminante: el que se provocará entre la "autoridad nacional", los intereses nacionales y la propia voluntad de la nación. Este enfoque intra-Estado es de relevancia principal.

Que mencionen el tratado que puso fin a las guerras europeas del siglo XVII resalta la importancia que le dan a los "cambios de ciclo". Westfalia puso fin a las regulaciones jurídico-políticas del Sacro Imperio Romano y para los autores estos escenarios de inflexión son de obligado estudio. Muchos de sus pensamientos hunden raíces en ellos.

En segundo término, les inquieta que el Estado esté perdiendo el monopolio del uso -legal- de la fuerza. Que no controle la exclusividad de uso del armamento, que no sea la única entidad con capacidad legal de poseerlo.

Citan, entre las fuerzas que retan a los Estados en este asunto, el terrorismo, el crimen organizado, el narcotráfico y las crisis explosivas de odio racial. Y, con ello, coinciden con la mayoría de analistas, salvo en el último aspecto.

Pero interesa fijarse con atención en estas conclusiones, porque tal y como expone su teoría estratégica, la acción de combate irá dirigida a los puntos débiles del enemigo antes que a otros. Está en sus principios de "guerra irrestricta más allá de los límites". Por ello, es relevante que los mencionen expresamente y con intención crítica además, porque lo consideran propio de un pensamiento estrecho y limitado. Son los siguientes: conflictos de raíz política, racial, religiosa, cultural y étnica, en el nivel intranacional; crimen organizado de nivel regional; piratería y terrorismo, en el nivel que podemos llamar "apátrida"; movimientos religiosos, crimen organizado de nivel global; y tráfico de armas de raíz económica, en el nivel supranacional.

Como final de su crítica añaden por su cuenta, como amenazas asimétricas del inmediato futuro, a las compañías que depredan beneficios con intención monopolista, así como aquellas de tamaño global que no dudarán en retar a las autoridades nacionales en persecución de sus intereses empresariales y que pueden significar un impacto serio en la economía mundial.

Detecto en el añadido influencias, casi seguro, de su reciente historia; pero esas mismas también les liberan de un discurso que, en Occidente, "debe ser" políticamente correcto. No necesitan serlo siempre que respeten su propia idiosincrasia y cultura, claro está.

Un ejemplo de lo que digo lo tenemos si observamos cómo diseccionan sin ambages los efectos de las tensiones del poder que dieron paso a las nacionesEstado "asistidas por una guerra de hierro y sangre". Del mismo modo afirman que la transición, desde ellas, a la globalidad no deja ninguna vía que evite la colisión de enormes intereses de bloques.

Esa libertad de "pensar y decir" les permite insistir en la inutilidad de la guerra clásica como herramienta última de resolución de conflictos. Insistencia 
muy llamativa, por otra parte. Prestan especial atención a guerra clásica, no lo olvidemos. De hecho, a continuación sostienen que la humanidad no tiene razones en absoluto para sentirse aliviada por ello. Simplemente, hemos sustituido las guerras sangrientas por "guerras sin sangre" hasta donde se ha podido hacerlo.

De nuevo, Sun Tzu, deja su aroma en estos pensamientos: "Porque obtener cien victorias en cien batallas no es el colmo de la habilidad. Someter al enemigo sin librar combate es el colmo de la habilidad"19.

Estiman que, en las guerras futuras, las hostilidades serán de otro tipo. Lo financiero hará que las naciones sean derrotadas sin derramar una sola gota de sangre. Y añado yo, en campos de batalla clásicos, porque sangre se derramará, aunque no sea del modo "clásico". Debemos dedicar unos momentos a reflexionar sobre ello.

Hoy en día, en esta tercera década del siglo XXI que ahora empieza, la acción especuladora en los mercados está provocando situaciones de gran calado en las economías de muchos países. Hasta tal punto que resulta muy difícil arriesgar un pronóstico de cómo las cosas sucederán.

Personalmente percibo que este será uno de los escenarios de "combate" en el futuro inmediato; y lo que es peor, nadie arriesga un análisis sobre quiénes serán los contrincantes implicados; ni siquiera si nosotros mismos estaremos bajo amenaza.

La completa situación política mundial es inescrutable porque los actores se muestran ocultos y el mandato de Tzu del "arte de la impostura" ha llegado a niveles de actuación sublimes.

Mientras que restringimos el "teatro de operaciones" con espíritu taxativo, hemos convertido nuestro mundo en un "campo de batalla" en el más amplio sentido. Y, según los autores, en este escenario de guerra la gente todavía pelea, saquea y mata como antes, pero con armas más sofisticadas y medios más avanzados. De alguna forma menos sangrienta, pero exactamente igual de brutal; nada que esperar, pues, del eterno sueño de paz tan propio de nuestra raza.

En Oriente, se sigue pensando que la guerra no podrá desaparecer en un previsible futuro, ya sea en su modalidad sangrienta o en forma no letal ni lesiva. En Oriente, siguen priorizando el pensamiento sobre aquello que debe ser considerado para alcanzar la Victoria. O sea, que están alerta y en estado beligerante $\mathrm{y}$, lo principal, quieren prevalecer.

Interesa, por tanto, conocer cómo sienten el escenario, porque "su guerra" es un conflicto en sentido amplio que se desplegará en un "campo de batalla sin límites definidos". En este escenario ya no se puede confiar exclusivamente en fuerzas armadas de estilo clásico. Será un enfrentamiento de amplio

\footnotetext{
${ }_{19}$ Sun Tzu, "El Arte de la Guerra”, Editorial Troquel, Buenos Aires, noviembre 1993, pág 59
} 
espectro que implicará a la globalidad de la población en una u otra dimensión en este nuevo tipo de batalla. Lo expresan muy gráficamente desdiciendo a Clemenceau: “(...) Esta es la clase de guerra en la era de la globalidad. Aunque sea tan solo un aspecto de ello, es un aspecto sorprendente".

\section{Referencias bibliográficas:}

Aznar Fernández-Montesinos, Federico, "Los valores militares y el bushido". Bueno Martínez, Gustavo, Cuestiones proemiales. Disponible en: www. filosofia.org/filomat/df244.htm

Bueno Martínez, Gustavo, Teoría de la Sociedad política y del Estado.

Bueno Martínez, Gustavo, Teoría Sintáctica del Poder Político. Disponible en: www.filosofia.org

Confucio,"The Family and the State" (https://plato.stanford.edu/entries/ confucius/\#FamiStat)

Hernández-Pacheco, Javier, "Oficial y caballero. El paradigma militar en una cultura posheroica” en VV.AA. En una sociedad posheróica: la transformación del paradigma militar. Monografía del CESEDEN núm. 127.

Liang, Qiao y Xiangsui, Wang, Unresticted Warfare, 1999.

Shi, Li, "The Military History of Remote Antiquity Period and The Three Dynasties" DeepLogic (ebook)

Tsé, Lao, Tao Te Ching.

Tzu, Sun, “El Arte de la Guerra”, Editorial Troquel, Buenos Aires, noviembre 1993. 